\title{
Educación en salud como parte del currículo escolar: de la teoría a la práctica
}

Health education as a part of scholar curriculum: from theory to practice

\section{Educação em Saúde como parte do currículo escolar: da teoria a prática}

Fernanda Grosselli ${ }^{1}$, Silvana Ceolin ${ }^{2}$, Marjoriê da Costa Mendieta ${ }^{3}$, Glaucia Hohengerber ${ }^{4}$, Afra Suelene de Sousa ${ }^{5}$, Rita Maria Heck ${ }^{6}$

${ }^{1}$ Enfermeira. Graduada pela Faculdade de Enfermagem da Universidade Federal de Pelotas - UFPel. ${ }^{2}$ Silvana Ceolin. Mestre em Enfermagem. Doutora do Programa de Pós-Graduação em Enfermagem (PPG-Enf) da UFPel, em cotutela com a Universidad de Alicante (Cultura de los Cuidados). Universidade Federal de Pelotas (UFPel). Brasil.

${ }^{3}$ Enfermeira. Doutoranda da Programa de Pós-Graduação em Enfermagem da Universidade Federal de Pelotas. Universidade Federal de Pelotas (UFPel). Brasil.

${ }^{4}$ Enfermeira pela Universidade Federal de Pelotas (UFPel). Universidade Federal de Pelotas (UFPel). Brasil ${ }^{5}$ Doutora em Enfermagem. Professora Associada da Faculdade de Enfermagem da UFPel. Universidade Federal de Pelotas (UFPel). Brasil

${ }^{6}$ Doutora em Enfermagem. Professora titular do PPG-Enf da UFPel. Universidade Federal de Pelotas (UFPel). Brasil Cómo citar este artículo en edición digital: Grosselli, F., Ceolin, S., Mendieta, M.C., Hohenberger, G.F., Sousa, A.S., \& Heck, R.M. (2017). Educación en salud como parte del currículo escolar: de la teoría a la práctica. Cultura de los Cuidados (Edición digital), 21(49). Recuperado de http://dx.doi.org/10.14198/cuid.2017.49.20.

Correspondencia: Fernanda Grosselli.Rua Padre Pedro Casara, no 141 - Centro. Fagundes Varela / RS - Brasil. CEP: 95333-000 Correo electrónico: fergrosselli@gmail.com

Recibido: 11/03/2017; Aceptado: 10/05/2017

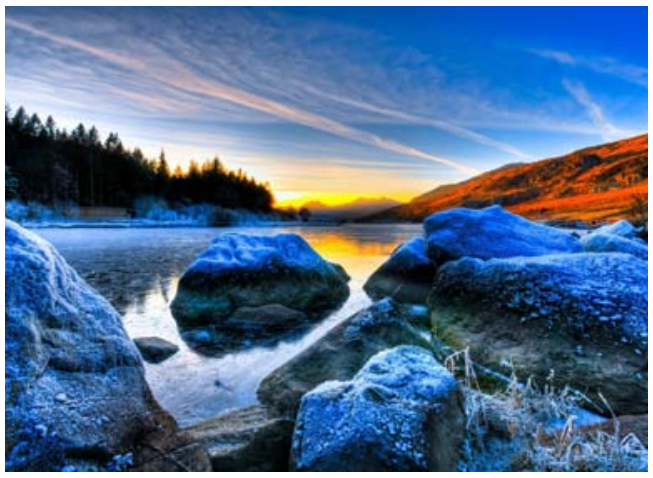

\section{ABSTRACT}

This research was aimed to know how health education is developed in two public elementary schools in Pelotas/RS/Brazil. Also, it is a qualitative study, which was carried out with eight participants, from which two were education coordinators and six teachers. Data was collected in August 2014 through semi- structured interviews and documental analysis of the political-pedagogical projects and the schools' plan of studies. These were analyzed according to Minayo's proposal. It was possible to find that teachers from different subjects have been developing punctual activities in health education. In addition, it is important to highlight the necessity to train these teachers about the theme and the importance of effective articulations among health services and educational institutions to strengthen the education activities on educational health

Keywords: Health Education, school health, curriculum.

\section{RESUMEN}

La investigación tuvo como objetivo conocer cómo se desarrolla la educación en salud en dos escuelas primarias de Pelotas/RS/ Bra- 
sil. Estudio cualitativo, realizado con ocho participantes, de los cuales dos coordinadores de enseñanza y seis maestros. La recolección de datos ocurrió en agosto 2014 mediante entrevistas semiestructuradas y análisis documental de los proyectos político-pedagógicos y planes de estudio. Las informaciones fueron analizadas por la propuesta operativa Minayo. Los hallazgos obtenidos resaltan que maestros de distintas disciplinas han desarrollado actividades pontuales de educación en salud. Se destaca la necesidad de capacitación de los maestros y de construcción de vínculos efectivos entre los servicios de salud y las instituciones de educación superior para fortalecer las actividades de educación en salud en la escuela.

Palabras clave: Educación en salud, salud escolar, currículo.

\section{RESUMO}

A pesquisa objetivou conhecer como a educação em saúde é desenvolvida em duas escolas municipais de ensino fundamental de Pelotas/RS/Brasil. Estudo de caráter qualitativo, realizado com oito participantes, sendo dois coordenadores de ensino e seis professores. Os dados foram coletados em agosto de 2014 por meio de entrevista semiestruturada e análise documental dos projetos político-pedagógicos e dos planos de estudos das escolas. Estes foram analisados seguindo a proposta operativa de Minayo. Constatou-se que os professores das diferentes disciplinas vêm desenvolvendo atividades pontuais de educação em saúde. Destaca-se a necessidade de capacitações sobre a temática para os professores e de articulações efetivas entre serviços de saúde e instituições de ensino superior para fortalecer as atividades de educação em saúde escolar.

Palavras Chave: Educação em saúde, saúde escolar, currículo.

\section{INTRODUÇÃO}

A interface da saúde com a educação está presente durante todo o processo de viver humano de maneira muito expressiva. Este processo é indispensável no desenvolvimento biopsicossocial infantil e na formação dos sujeitos sociais e políticos. Neste sentido, a escola tem representado um importante local para o encontro entre saúde e educação, abrigando amplas possibilidades de formação do cidadão (Casemiro; Fonseca; Secco, 2014).

A idade escolar é um período de transformações, aquisição de conhecimentos, formação de hábitos e valores. É, também, uma fase determinante na vida dos indivíduos, que, se trabalhada de forma dialogada e conectada com a cultura local, pode conduzir à formação de cidadãos críticos, reflexivos e conscientes de suas decisões. As crianças e adolescentes também atuam como multiplicadores dos saberes construídos no interior da escola, transmitindo-os para a sua família e a comunidade (Brasil, 2007).

Diante dessas perspectivas, em 1997, o Ministério da Educação criou os Parâmetros Curriculares Nacionais (PCNs) - nos quais os temas ética, meio ambiente, orientação sexual, pluralidade cultural e saúde são considerados transversais podendo serem trabalhados por todas as disciplinas curriculares, de forma contextualizados com as diferenças locais e regionais. Esta é uma maneira de incluir as questões sociais no currículo escolar, visando à compreensão da realidade social, dos direitos e responsabilidades cidadãs relacionadas à vida pessoal e coletiva (Brasil, 1997a).

A partir dos PCNs, a educação em saúde pode ser entendida como um processo que ultrapassa o paradigma biológico no entendimento das questões de saúde e doença, englobando determinantes culturais e sociais no 
processo de ensino-aprendizagem. Por isso, pressupõe mudanças nas estratégias pedagógicas, para conferir participação ativa dos sujeitos no seu processo de cuidado em saúde.

Esta perspectiva de educar está vinculada ao desenvolvimento de habilidades para pensar e agir de forma consciente diante da vida em sociedade, em um processo que se harmoniza com a construção de identidade, autonomia e liberdade para gerenciar a própria aprendizagem e o resultado dela em intervenções solidárias (Fini, 2008).

No entanto, apesar das iniciativas governamentais relacionadas à educação em saúde na escola, se questiona como os professores tem conseguido implementar o que está previsto nos PCNs.

Diante desse panorama, este estudo teve como objetivo conhecer como a educação em saúde é desenvolvida em duas escolas municipais de ensino fundamental.

\section{MATERIAL E MÉTODO}

A metodologia do estudo seguiu a abordagem qualitativa. A pesquisa ocorreu em duas escolas municipais de ensino fundamental da cidade de Pelotas, Rio Grande do Sul/Brasil, sendo uma na área urbana e outra rural. Ambas estão situadas em regiões de vulnerabilidade social e atendem a educação infantil, o ensino fundamental e o Programa de Educação para Jovens e Adultos (PEJA).

A pesquisa constituiu-se de oito participantes, selecionados por sorteio aleatório. Tal sorteio foi realizado entre os professores da disciplina de Ciências, selecionando-se um por escola. A disciplina foi elencada por tradicionalmente abordar conteúdos relacionados à saúde. Entendendo saúde como um tema transversal, foram incluídos, também por sorteio, mais dois professores por escola, sendo um de história, um de geografia, um de matemática e um de português. Também foram incluídos no estudo um coordenador de ensino de cada escola, por os mesmos estarem diretamente envolvidos na gestão do ensino.

$\mathrm{Na}$ identificação dos participantes foram utilizadas as letras iniciais de seus nomes, seguidas da sua idade e profissão. O estudo obedeceu as normas éticas de pesquisa com seres humanos e recebeu parecer favorável do Comitê de Ética e Pesquisa da Faculdade de Enfermagem da Universidade Federal de Pelotas sob o parecer $020 / 2011$.

A coleta de dados foi realizada no mês de agosto de 2014 a partir da análise documental do projeto político pedagógico e do plano de estudos de uma das escolas, buscando identificar a inserção dos conteúdos de educação em saúde nas disciplinas do currículo escolar. A outra escola não disponibilizou o material para análise. Os professores e coordenadores de ensino participantes responderam a entrevista semiestruturada (Polit e Beck, 2011).

A análise dos dados foi desenvolvida por meio da proposta operativa (Minayo, 2010), que resultou em dois temas: "A educação em saúde no contexto escolar do ensino fundamental" e "as dificuldades encontradas pelos professores para o desenvolvimento da educação em saúde", na qual este artigo abordará o primeiro tema.

\section{RESULTADOS E DISCUSSÃO}

Dos oito sujeitos participantes da pesquisa, seis são do sexo feminino. A idade dos entrevistados variou de 30 a 51 anos e o tempo de trabalho variou de 4 a 32 anos. A carga horária desempenhada pelos profissionais oscilou de 40 a 60 horas semanais. Entre os oito sujeitos, sete possuem pós-graduação e um referiu ter iniciado, mas não concluído devido a falta de 
tempo. A professora de geografia e a professora de história ministram também a disciplina de ensino religioso.

Ao analisar o projeto político-pedagógico da escola rural, encontrou-se o seguinte objetivo educacional: "valorização da vida e a construção do homem capaz de compreender e interferir no meio, como agente de transformação", com dois objetivos específicos do ensino fundamental, que deixam clara a necessidade de se abordar a temática saúde em sala de aula: "perceber-se integrante, dependente e agente transformador do ambiente, identificando seus elementos e as interações entre eles, contribuindo ativamente para a melhoria do meio ambiente; conhecer e cuidar do próprio corpo, valorizando e adotando hábitos saudáveis como um dos aspectos básicos da qualidade de vida e agindo com responsabilidade em relação à sua saúde e à saúde coletiva”.

No texto do projeto político-pedagógico, especialmente nestes objetivos apresentados, observa-se a ênfase do escolar como agente de transformação. Esta questão remete ao referencial de Paulo Freire que tem sido materializado e reinventado na contemporaneidade. Seus pressupostos vêm se revelando em um paradigma inspirador de políticas e práticas de educação nos espaços de ensino ao evidenciar a necessidade de superação de formas hegemônicas de agir e pensar, e proposição de uma educação eticamente comprometida com liberdade e a humanização dos sujeitos (Saul, 2014).

Nas entrevistas, os professores afirmam que a educação em saúde, de certa forma, vem sendo abordada nas disciplinas de ciências, geografia, história, português e ensino religioso. Entretanto, ao analisar o plano de estudos, as disciplinas nas quais aparecem conteúdos vinculados à educação em saúde são somente ciências, história, geografia e educação física.

No plano de estudos da disciplina de ciências, identificam-se os seguintes temas relacionados à saúde: corpo humano; adoção e valorização de hábitos saudáveis em prol de melhor qualidade de vida; higiene pessoal; educação ambiental - poluição, reciclagem, preservação; hábitos alimentares; higiene dos alimentos; acidentes e prevenção; tratamento dos resíduos sólidos - reciclar, reutilizar e reduzir; animais transmissores de doenças; prevenção de acidentes com animais; prevenção às doenças e doenças transmitidas pelo ar.

Nas disciplinas de história e geografia verificam-se os seguintes conteúdos relacionados à saúde no plano de estudos: reconhecimento do outro, do meio ambiente, de responsabilidade; mapeamento do corpo; o homem e a natureza; aproveitamento de recursos naturais; ação do homem sobre a natureza; interação homem e meio ambiente; condições de vida no bairro; preservação e conservação dos ambientes, reciclagem, redução da produção de lixo; serviços de saúde no bairro.

Apesar dos planos de estudos apresentarem algumas questões de qualidade de vida e educação ambiental, apontam para uma prática de ensino onde muitas questões de saúde fundamentam-se no modelo biomédico, pois diversos tópicos enfatizam o corpo e a doença, como "mapeamento do corpo", "corpo humano", "higiene", "animais transmissores de doenças", "prevenção às doenças" e outros. Com isso, percebe-se que há um foco em questões relacionadas à doença e ao higienismo, o qual fragiliza a inserção de aspectos culturais que envolvem a saúde no cotidiano da sala de aula.

Apesar da existência de um plano de estudos, os professores tem a flexibilidade de abordar estas temáticas de maneiras distintas, 


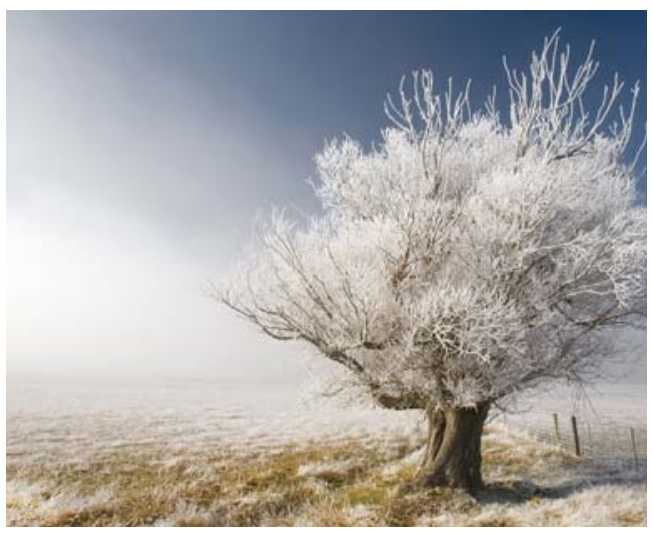

as quais poderiam inclusive incluir os aspectos culturais na perspectiva dos conteúdos pré-estabelecidos, visto que atualmente isso depende muito do professor, variando de um para outro.

Os discursos a seguir demonstram que os professores pouco valorizam a cultura e realidade local, enfatizando temas pré-estabelecidos e embasados no modelo biomédico:

Dentro da Geografia, nós trabalhamos. Mas dentro, mais, da parte histórica. Como as epidemias dizimaram as populações na Europa [...] as vacinas [...] o quanto os antibióticos e a descoberta da penicilina ajudou a diminuir as taxas de mortalidade (L.C.C., 31a, Professora de Geografia).

$\mathrm{Na}$ quinta série nós estudamos os reinos dos seres vivos né, onde nós estudamos o reino monera e aí se fala muito sobre as bactérias, antibióticos, enfim né, doenças causadas por bactérias, por vírus né e aí se bate firme nessa questão do vírus que é mortal, a AIDS [...] Depois do reino monera vem o protista, onde estão os protozoários e então as doenças causadas por protozoários [...] Depois, nós passamos pro reino fungi e aí também se aborda saúde, quer dizer, doença [...] Na sétima série se estuda o corpo humano. Aí então, se dedica da célula aos sistemas, com todas as possibilidades de doen- ças né ou de saúde (J.F.A.I., 53a, Professor de Ciências).

A partir destes discursos percebe-se que há uma tendência em pensar a saúde de forma assistencialista e higienista, reduzida ao corpo biológico, executando ações de forma isolada (Santos e Bógus, 2007). Isso pode ser influenciado por fatores como a formação acadêmica destes profissionais e também, os próprios planos de estudos das escolas, apontados anteriormente.

No entanto, esta não é uma realidade de todos os professores, como se constata na fala a seguir em que uma realidade vivenciada influenciou na dinâmica pedagógica:

Agora mesmo a gente tem uma menina que está grávida [...] Então, aí tu procura já falar da gravidez na adolescência, os riscos de DST's, a consequência de um ato impensado, sem proteção né (M.L.F.S, 51a, Professora de Ciências).

Este discurso aponta para um esforço de transversalizar temas no currículo, porém não há uma sequência de atividades e assuntos a serem abordados em cada disciplina. Assim, os professores aproveitam momentos de questionamentos da turma e os próprios acontecimentos do dia-a-dia para extraírem temas e direcionar discussões, como relatado também nos discursos que seguem:

Não faz parte do meu conteúdo, mas faz parte do meu conteúdo discutir, fazer refletir, pensar, formar uma opinião e a partir disso escrever alguma coisa. Então, pra eles poderem refletir, eu tenho que ficar provocando eles (J.P.B., 50a, Professora de Português).

A sala de aula é um universo tão grande de discussão, de conversa, que a gente não pode deixar passar... Eu acho que não pode perder aquele momento de questionamento e também não falar bobagem, eu também me preocupo bastante com isso. O que eu falo é até onde 
eu acho que eu posso, depois eu não falo mais (L.S.V., 40a, Professora de História e Ensino Religioso).

O esforço dos professores em abordar os temas transversais vem ao encontro da complexidade que se tornou o trabalho docente, o qual não tem mais apenas a função de transmitir conteúdos para um público homogêneo, mas requer competências relacionadas a um trabalho vinculado com a realidade social e cultural dos escolares, incluindo componentes éticos, familiares, emocionais e de saúde (Lelis, 2012).

Além disso, de acordo com os PCN's (Brasil, 1997b) a abordagem dos diversos conteúdos deve ser realizada sob a perspectiva principal de saúde e não de doença. Os detalhes referentes a processos fisiológicos ou patológicos ganharão sentido na medida em que contribuírem para a compreensão dos cuidados em saúde a eles associados.

Os aspectos culturais do processo saúde-doença são muito importantes para trabalhar a educação em saúde, visto que para as discussões serem significativas ao educando e resultarem em conscientização, precisam ter interface com o seu contexto.

Apesar do envolvimento de algumas disciplinas no desenvolvimento de atividades de educação em saúde, ainda aparecem discursos que direcionam esta tarefa apenas à disciplina de ciências. É possível constatar que o próprio professor de ciências reforça tal concepção na fala a seguir.

Eu acho que ciências tem mais espaço até pra abordar né. Tem outras disciplinas que não sei se chegam a fazer abordagens né. Talvez esporadicamente, quando surge um assunto na sala de aula [...] Mas eu acho que ciências é que deve conversar mais com os alunos sobre isso, prepara-los (J.F.A.I., 53a, Professor de Ciências).
Nós temos uma lista enorme de conteúdos a cumprir [...] Então, assim, acaba ficando, a gente acaba esperando mais pra disciplina das ciências biológicas trabalhar com essa área né (L.C.C., 31a, Professora de Geografia).

Corroborando com estes resultados, um estudo também demonstrou a prevalência da concepção especialista, na qual os professores participantes afirmaram que o responsável pelo tema de educação em saúde seria apenas o professor de Ciências, por ser ele o mais habilitado devido a sua formação profissional (Santos e Bógus, 2007).

Outro fator relacionado ao ensino de saúde na escola envolve a utilização de metodologias adaptadas à realidade dos educandos. No entanto, por muito tempo, a aprendizagem do aluno era considerada passiva, consistindo basicamente na memorização de informações. O papel do professor era o de transmissor e expositor de um conteúdo pronto e acabado. Ou seja, o uso de metodologias dinâmicas e interativas era considerado perda de tempo, uma atividade que perturbava o silêncio ou a disciplina da classe (Souza, 2007).

No que se refere à metodologia para a abordagem o tema saúde, os professores demostram criatividade e utilizam diversos recursos didáticos, conforme observado nos discursos abaixo:

Por exemplo, a questão do lixo, eu já trouxe pra eles vídeos [...] Trago fotos, sempre procuro trazer alguma coisa [...] Diferente de ficar copiando no quadro e mandando o aluno copiar (J.P.B., 50a, Professora de Português).

Eu uso muito DVD [...], que dá muito certo, assim, é muito legal. E, fazemos pesquisa também [...] eu procuro simplificar as coisas pra eles, mas também dar uma linguagem buscada de livros e tal (J.F.A.I., 53a, Professor de Ciências). 
$\mathrm{Na}$ disciplina de religião, no projeto profissões, eu abordo as profissões da saúde, principalmente, que é a que eles mais se interessam [...] Então, eu sempre convido um profissional pra vir aqui, pra fazer uma palestra (L.S.V., 40a, Professora de História e Ensino Religioso).

Os recursos didáticos configuram-se como um importante auxílio ao educador no processo de ensino e de aprendizagem. Refere-se a todo material utilizado no ensino do conteúdo proposto, havendo uma infinidade de recursos que podem ser explorados, desde o quadro de giz, jogos, mídias, até passeios para pesquisa de campo (Souza, 2007).

A literatura reforça a necessidade de diversificar formas de ensinar e aprender para construir um processo interativo e significativo. Neste sentido, a problematização do processo de ensino-aprendizagem com o uso de metodologias ativas constitui-se em uma perspectiva para o desenvolvimento de uma relação dialógica entre educador e educando, com a finalidade de construir conhecimentos a partir da vivência de experiências significativas (Mitre et al, 2007).

O propósito do professor ao utilizar esses recursos deve ser o de conseguir que os educandos sintam-se agentes ativos no processo de ensino, compreendendo os conteúdos e utilizando o conhecimento adquirido em sua realidade (Souza, 2007). A utilização de metodologias ativas é uma maneira criativa e eficiente para atrair a atenção dos alunos, incentivando-os na busca por conhecimento de forma dinâmica e participativa, fazendo das aulas momentos mais significativos e proveitosos.

Os professores e coordenadores, participantes desta pesquisa, indicaram como parcerias atuantes no desenvolvimento de atividades de educação em saúde na escola, a Unidade Básica de Saúde, mais especificamente os profissionais da odontologia, e a Universidade Federal de Pelotas. As demais profissões da saúde não estão inseridas de maneira significativa no espaço escolar, realizando ações isoladas. Tais parcerias são descritas por alguns participantes:

A dentista vem aqui e aplica flúor, essas coisas [...] acho que uma enfermeira veio fazer alguma atividade. Mas não é constante, assim, não é com bastante frequência, não. É pouco, poderia ter muito mais (L.C.L.J., 30a, Professor de Matemática).

A gente consegue fazer esse elo sim, mais com relação à saúde bucal assim, em função dos dentistas [...] Com relação às demais, fica faltando (L.S.P., 35a, Coordenadora de Ensino).

A universidade [...] geralmente todos os anos vem aqui fazer palestras. Eu gosto muito, acho interessante (M.L.F.S., 51a, Professora de Ciências).

Estes relatos reafirmam que as atividades de educação em saúde realizadas no âmbito escolar são pontuais, focadas no modelo biomédico. Em nenhum dos relatos foram citadas as Unidades Básicas de Saúde, que poderiam ser aliadas neste contexto, a fim de promover a educação em saúde escolar de maneira ativa e efetiva, em parceria com os professores.

Aliar universidade e escola é de grande valia para ambas instituições pois possibilita aos acadêmicos dinamizar sua formação, e para a escola e a sociedade, representa uma alternativa de melhoria da educação e formação de cidadãos críticos (Scheid; Soares; Flores, 2009).

Os discursos dos profissionais da educação básica desta pesquisa envidenciam que os mesmos vêm desenvolvendo ações de educação em saúde da maneira que lhes é plausível, levando em consideração seus conhecimentos prévios sobre a temática e o pouco apoio recebido dos serviços de saúde. Essa realidade pode ser otimizada a partir da união da edu- 
cação básica com as instituições de saúde, no intuito de relativizar a compreensão reducionista de saúde, na qual as ações se concentram em transmitir informações sobre higiene e doenças.

Entendendo a educação em saúde como um dos pilares da atenção básica, as equipes interdisciplinares das Unidades Básicas de Saúde precisam perceber as escolas de seus territórios de abrangência como espaços propícios para o desenvolvimento dessas ações e buscar, junto aos professores e coordenadores, o estabelecimento de parcerias que irão refletir em qualificação do processo educativo em saúde e melhoria da qualidade de vida da população assistida.

\section{CONSIDERAÇÕES FINAIS}

A realização dessa pesquisa possibilitou conhecer os conteúdos de educação em saúde presentes no currículo escolar e como os mesmos são desenvolvidos pelos professores.

Os professores das diferentes disciplinas vêm desenvolvendo atividades pontuais de educação em saúde, nas quais se percebe uma fundamentação biomédica, pois em diversos momentos há ênfase no corpo e na doença durante a abordagem do tema. Ainda, no plano de estudos e no discurso de alguns participantes, os assuntos relacionados à temática saúde são associados como prioritário da disciplina de ciências.

As escolas em questão recebem pouco apoio das Unidades Básicas de Saúde, que poderiam fortalecer abordagens dinâmicas de saúde. A universidade é indicada como uma frutífera parceira da escola no desenvolvimento de tais atividades, porém suas ações ainda são momentâneas e descontinuadas.

A análise realizada por este estudo constata a necessidade de estreitar vínculos entre as áreas da saúde e da educação e realizar periódicas qualificações aos profissionais, para que uma conceituação positiva de saúde e sociocrítica de educação faça parte de suas ações. Esta perspectiva favorece o processo de conscientização e construção da autonomia dos sujeitos no seu cuidado à saúde e condutas de vida.

Como encaminhamento deste estudo destaca-se a necessidade de os gestores realizarem periódicas revisões nos PNC's e inserirem representantes das escolas nestas discussões, os quais conhecem as possibilidades e necessidades do contexto escolar Também recomenda-se a realização de outras pesquisas junto à comunidade escolar, a fim de construir um panorama de como o tema saúde vem sendo trabalhado nas escolas públicas brasileiras.

\section{REFERÊNCIAS}

- Brasil. (1997a). Ministério da Educação. Parâmetros Curriculares Nacionais: introdução aos parâmetros curriculares nacionais. Ensino de $1^{\text {a }}$ a $4^{\text {a }}$ séries. Brasília: Ministério da Educação. Disponible en http://portal.mec.gov.br/ seb/arquivos/pdf/livro01.pdf

- Brasil. (1997b). Ministério da Educação. Parâmetros Curriculares Nacionais: saúde. Brasília: Ministério da Educação. Disponible en http://portal.mec.gov.br/seb/ arquivos/pdf/saude.pdf

- Brasil. (2007). Decreto n 6.286 de 5 de dezembro de 2007. Institui o Programa Saúde na Escola. Disponible en http://www.planalto.gov.br/ccivil_03/_ato20072010/2007/decreto/d6286.htm

- Casemiro, J.P., Fonseca, A.B.C., Secco, F.V.M. (2014). Promover saúde na escola: reflexões a partir de uma revisão sobre saúde escolar na América Latina. Ciência e Saúde Coletiva, 19(3), 829-40. Disponible en http://www.scielo. br/pdf/csc/v19n3/1413-8123-csc-19-03-00829.pdf

- Fini, M. I. (2008). Proposta curricular do Estado de São Paulo. São Paulo: SEE.

- Lelis, I. (2012). O trabalho docente na escola de massa: desafios perspectivas. Sociologias, 14(29), 152-174. Disponible en http://www.scielo.br/pdf/soc/v14n29/ a07v1429.pdf

- Minayo, M.C.S. (2010). O desafio do conhecimento: pesquisa qualitativa em saúde. 12.ed. São Paulo: Hucitec.

- Mitre, S. M. et al. (2008). Metodologias ativas de ensino-aprendizagem na formação profissional em saúde: debates atuais. Ciência \& Saúde Coletiva, 13(Sup2),21332144. Disponible em http://www.scielo.br/pdf/csc/ v13s2/v13s2a18.pdf 
- Polit, D.F., Beck, C.T. (2011). Fundamentos de pesquisa em enfermagem: avaliação de evidências para a prática de enfermagem. 7.ed. Porto Alegre: Artmed. 669p.

- Santos, K.F., Bógus, C.M. (2007). A percepção de educadores sobre a escola promotora de saúde: um estudo de caso. Revista Brasileira de Crescimento e Desenvolvimento Humano, 17(3), 123-133. Disponible en http://www. revistas.usp.br/jhgd/article/viewFile/19854/21927

- Saul, A. M. (2014). Políticas e práticas educativas inspiradas no pensamento de Paulo Freire: pesquisando diferentes contextos. Currículo sem Fronteiras, 14(3), 129-142. Disponible en de http://www.curriculosemfronteiras.org/vol14iss3articles/saul.pdf
- Scheid, N.M.J., Soares, B.M., Flores, M.L.T. (2009). Universidade e Escola Básica: uma importante parceria para o aprimoramento da educação científica. Revista Brasileira de Ensino de Ciência e Tecnologia, 2(2),64-74. Disponible em http://www.sinect.com.br/anais2009/ artigos/4\%20Ensinodebiologia/Ensinodebiologia_Artigo6.pdf

- Souza, S.E. (2007). O uso de recursos didáticos no ensino escolar. Arquivos do Mudi, 11(2),110-114. Disponible en http://www.dma.ufv.br/downloads/MAT\%20103/2015II/slides/Rec\%20Didaticos\%20-\%20MAT\%20103\%20 -\%202015-II.pdf

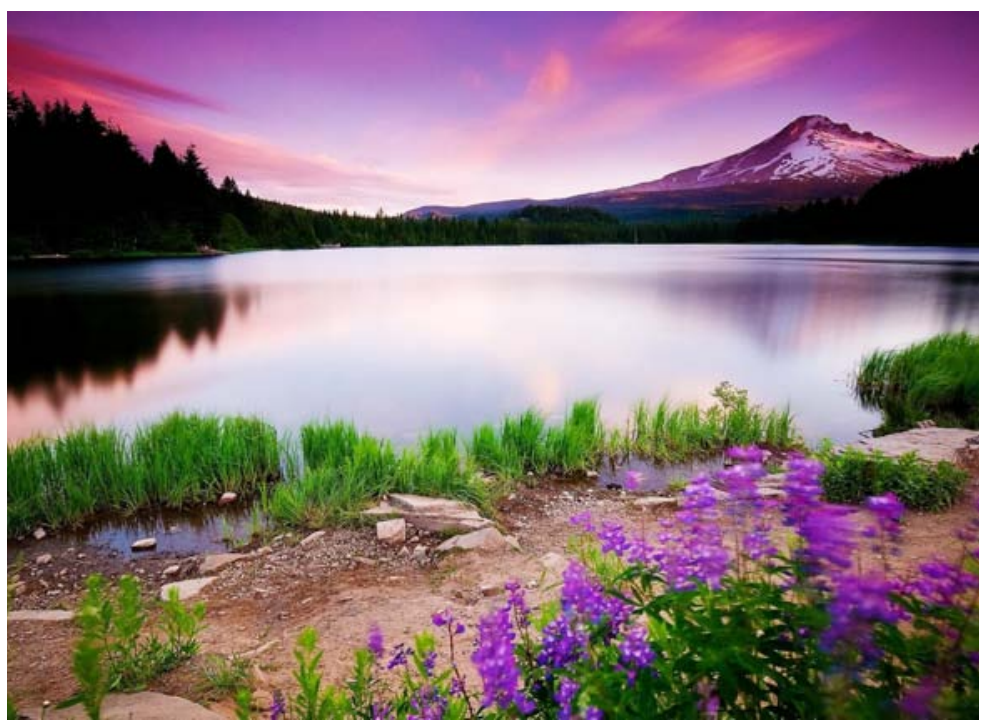

